\title{
UROLOCIA EN IMACENES
}

Arch. Esp. Urol. 2009; 62 (8): 673-674

\section{"ABSCESO PROSTATICO MULTILOCULAR GIGANTE"}

Rodolfo Orozco Fariñas, José Ignacio Iglesias Prieto, Jorge Massarrah Halabi, José María Mancebo Gómez, Enrique Pérez-Castro Ellendt y Ricardo Molezun Goicoal?

Unidad de Urología. Clínica La Luz. Madrid. España. Departamento Radiodiagnósticol. Clínica La Luz. Madrid. España.

aciente FCPV, varón de 60 años, con antecedentes de tumor cerebral (glioblastoma multiforme), diagnosticado en el año 2007 y tratado mediante cirugía y quimioterápia, así como hemorroidectomía reciente, que ingresa el 14 de abril de 2008 por retención urinaria y "tensión dolorosa" perineal.

Tacto rectal: aumento de volumen prostático grado III-IV, consistencia blanda y fluctuante, con temperatura normal, ausencia de dolor, asimetría a predominio derecho y límites prostáticos imprecisos.

Ecografía transrrectal: Próstata

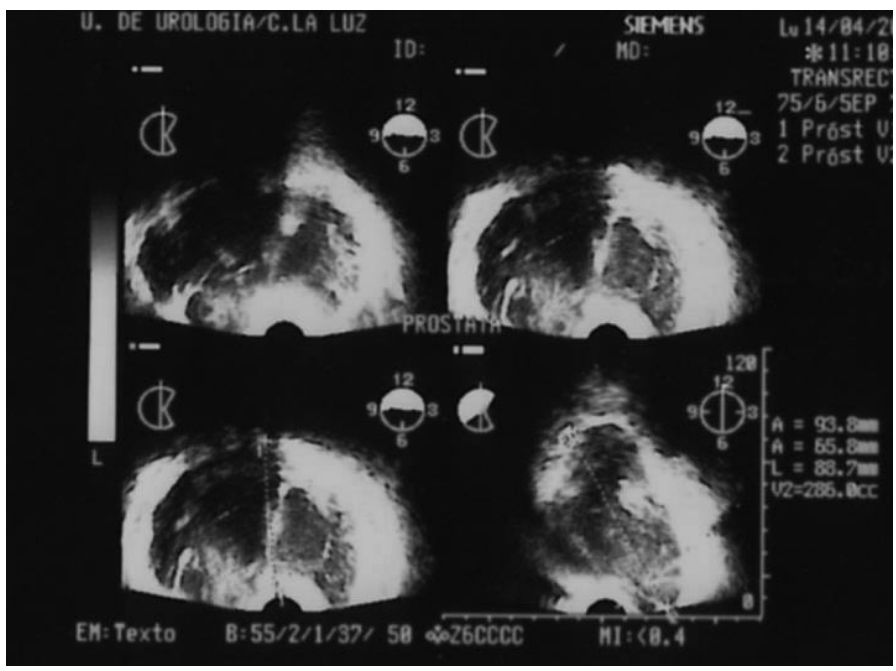

FIGURA 1. Ecografía transrectal. Cortes coronales y sagital de gran masa heterogénea y compleja irregularmente delimitada. Volumetría.

con aspecto de masa heterogénea, de contornos irregulares y cápsula imprecisa en determinadas zonas, con áreas hipoecogénicas e hiperecogénicas. Predominio de hipotético lóbulo derecho. Volumen total de $286 \mathrm{ml}$. (Figura 1).

\section{CORRESPONDENCIA} Rodolfo Orozco Fariñas

Clínica La Luz

General Rodrigo, 8 28003 Madrid. (España).

drorozco9@hotmail.com

Trabajo recibido: 11 de octubre 2008. 
RMN: Masa quística en la teórica localización prostática con septos y realce homogéneo y lineal de su pared tras la administración de contraste. Ausencia de colección pelviana y de adenopatías significativas. Vesículas seminales normales. Vejiga de lucha. Diverticulosis de colon (Figuras 2 y 3 ).

El 15 de abril de 2008 se realiza abordaje endoscópico transuretral y resección con apertura de varias cavidades predominantemente derechas de contenido francamente purulento evacuándose aproximadamente 2 litros de pus fétido parduzco. $\mathrm{Se}$ reseca además vertiente cervical engrosada.

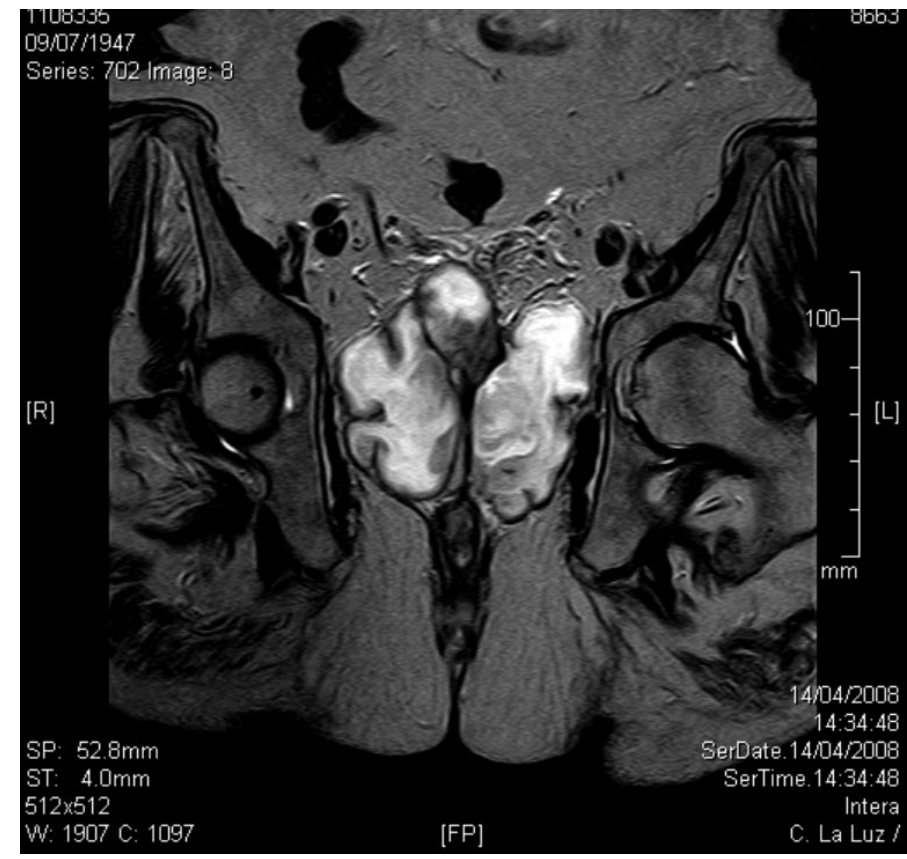

FIGURA 2. Resonancia magnética. Realce prostático.

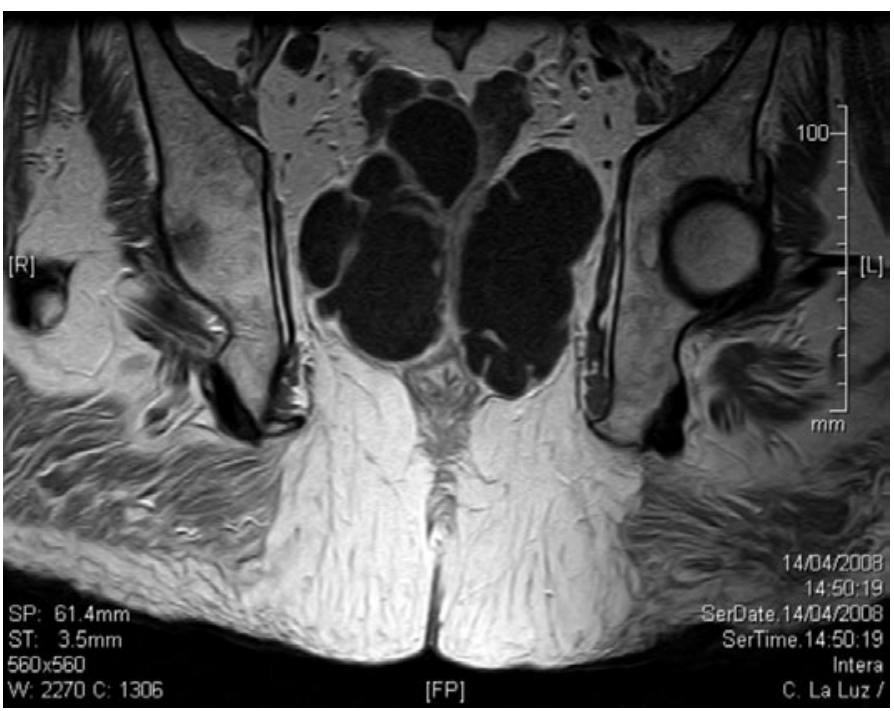

FIGURA 3. Resonancia magnética de la masa prostática quística con aspecto multilocular.

\section{Estudio anatomopatológico:} Hallazgos compatibles con prostatítis aguda con intensa infiltración neutrófila y necrosis supurativa, ausencia de granulomas y signos de hipertrofia muscular con esclerosis del cuello vesical.

Comentario: Se trata de un caso poco frecuente en la actualidad, en el que su condición de inmunodepresión y enfermedad de base e incluso hemonoidectomía previa pudieron influir en su evolución. 